\title{
Real-Time Dynamic Simulation of Korean Power Grid for Frequency Regulation Control by MW Battery Energy Storage System
}

\author{
Tae-Hwan Jin', Mo Chung ${ }^{2}$, Ki-Yeol Shin ${ }^{* 3}$,Herie Park, Geon-Pyo Lim ${ }^{5}$ \\ ${ }^{1}$ School of Mechanical Engineering, Yeungnam University, Gyeongsan, Gyeongbuk, Republic of Korea \\ e-mail: jinth@ynu.ac.kr \\ ${ }^{2}$ School of Mechanical Engineering, Yeungnam University, Gyeongsan, Gyeongbuk, Republic of Korea \\ e-mail: mchung@yu.ac.kr \\ ${ }^{3}$ School of Mechanical Engineering, Yeungnam University, Gyeongsan, Gyeongbuk, Republic of Korea \\ e-mail: shinky@ynu.ac.kr \\ ${ }^{4}$ Automotive Lighting LED-IT convergence Education, Yeungnam University, Gyeongsan, Gyeongbuk, \\ Republic of Korea \\ e-mail: bakery@ynu.ac.kr \\ ${ }^{5}$ Renewable \& ESS Group, KEPCO Research Institute, Daejeon, Republic of Korea \\ e-mail: kepcolim@kepco.co.kr
}

Cite as: Jin, T.-H., Chung, M., Shin, K.-Y., Park, H., Lim, G.-P., Real-Time Dynamic Simulation of Korean Power Grid for Frequency Regulation Control by MW Battery Energy Storage System, J. sustain. dev. energy water environ. syst., 4(4), pp 392-407, 2016, DOI: http://dx.doi.org/10.13044/j.sdewes.2016.04.0030

\begin{abstract}
The aim of this study was to develop a real-time dynamic simulator of a power grid with power plant and battery model. The simulator was used to investigate the frequency control characteristics of a megawatt-scale high-capacity energy storage system connected to the electric power grid. In this study, a lithium-ion secondary battery was chosen as one of the batteries for a grid-connected model. The dynamics of the model was analysed in both steady and transient states. The frequency control system of the battery model plays a role in regulating the grid frequency by controlling the power of energy storage systems according to process variables and grid frequencies. The power grid model based on the current power network of South Korea, included power plants, substations and power demands. The power supply is classified by the type of turbine generator as thermal, nuclear, hydro power, pumped power storage, combined power plants and batteries, including high-capacity energy storage systems rated for a maximum of $500 \mathrm{MW}$. This study deals with an installed capacity of $87.17 \mathrm{GW}$ and peak load of $77.30 \mathrm{GW}$ in the Korean power grid. For 24 hours of operation, the maximum and minimum power outputs were simulated as $61.59 \mathrm{GW}$ and $46.32 \mathrm{GW}$, respectively. The commercialized real-time dynamic simulation software ProTRAX was used. The simulation was conducted to observe the operation characteristics of the frequency control system during a breakdown of power plants, as well as under governor-free operation, auto generation control operation, and with the battery energy storage system connected. The results show that the model is valid for each power plant breakdown simulation. They also confirm that the output power and frequency controls of the battery operated well during simulations.
\end{abstract}

\section{KEYWORDS}

Korean power grid, Energy storage system, Frequency regulation, Real-time dynamic simulation, Governor-free, Auto generation control.

\section{INTRODUCTION}

Power grid frequency plays an important role as a real-time index that shows the stability of the grid. In case load variations or generator trips occur, different operation

\footnotetext{
* Corresponding author
} 
strategies are required to maintain a proper grid frequency for grid stability, such as demand prediction, generator power distribution and power reserve assurance. The power industry in South Korea has been improved through restructuring from 1990 to 2010, and the frequency retention rate was enhanced to $99.74 \%$ at the beginning of 2000 . However, a power outage occurred in 2011 across South Korea, and the government turned from a supply-based energy policy to a demand-based energy policy based on information and communications technology in 2013.

For maintaining the frequency as a real-time index at its target value, the active power is regulated as balancing supply and demand by called frequency regulation. Frequency regulation consists of primary control, secondary control and tertiary control which are obtained frequency regulation reserves in conventional power systems. Primary control called governor-free and secondary control called auto generation control play an important role to maintain frequency at a target value in real time. It has differentiated characteristics of power grids because of its various parameters such as droop, sensitivity of control, deployment time and deviation for deployment time that is reached fully [1]. However, since frequency regulation is conducted by coal power plants in a conventional power system, it has thresholds for meeting the deployment time and the deviation while frequency is reached at a target value [2]. Especially, coal power plants operate with $95 \%$ of plant total output for frequency regulation and the remaining 5\% is supported by governor-free power reserves in Korea. The power plant efficiency is varied according to fuel cost, and the facility aging is caused by frequency power output fluctuation [3].

In order to solve these problems, research on a high-power battery energy storage system for frequency regulation has been conducted around the world. The advantages of a battery energy storage system are the rapid response and the accuracy of the system to frequency deviation [4]. Also in the case of the battery energy storage system using frequency regulation, it occurs in the form of discharge and charge modes, and can reduce the participation rate of coal power plants for frequency regulation such as governor-free and auto generation control [5]. Likewise, in South Korea, research on a high-power battery energy storage system for frequency regulation has been conducted especially by the Korea Electric Power Corporation (KEPCO). KEPCO investigated the dynamic control mode of a battery energy storage system for frequency regulation in a range that maintains grid stability and developed a frequency regulation controller. First of all, they investigated the criteria setting the dynamic operating mode of Battery Energy Storage System (BESS) [6]. The State of Charge (SOC)-based control strategy of BESS has been also studied for providing power system frequency regulation in a bulk power system [7]. Next, they implemented a control system operated for frequency regulation [8]. Finally, they investigated that frequency regulation controller is implemented by a control algorithm for the demonstration on actual power plant with BESS [9]. The developed FRC was applied at Jocheon substation at Jeju Island and the controller was tested in June 2014 [10]. BESS facilities were also installed at Seo-Anseong substation (28 MW) and are being tested at Sin-Yongin substation (24 MW) as shown in Figure 1. The test will be extended to a 500 MW battery installation until 2017.

In order to apply high-power BESS, preliminary research is needed. The first step is verification of the control performance in the range for grid stability while the FRC of BESS is interconnected [11]. Conventional power plants have been easily controlled and maintained by a governor controller. However, BESS charges or discharges according to the grid state and has limitation of power output and duration. Therefore, it is necessary to connect the battery to the grid to determine the charge and discharge characteristics and lifetime of the battery and to pre-validate the performance of its controller. On the same time, 1 MW BESS for grid applications was presented [12]. The applications include a 
provision of frequency reserves, peak shaving and islanded operation of a micro grid. Typical limitations of BESS such as its capacity, degradation, life time and different profiles on grid applications were also reported.

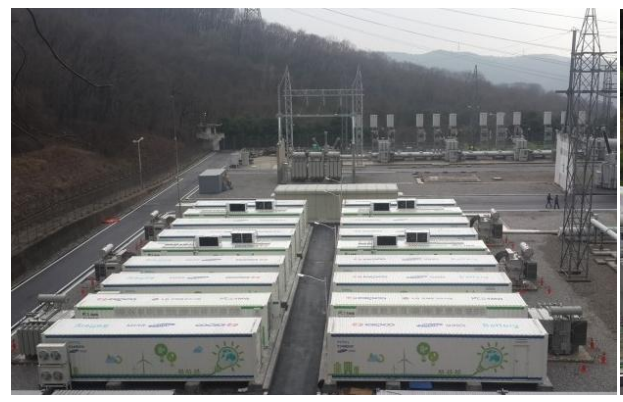

(a) 24 MW BESS

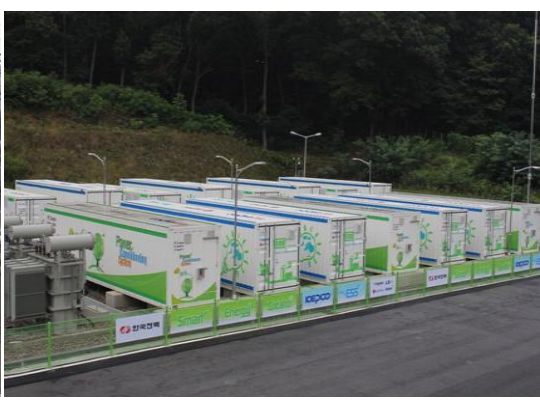

(b) $28 \mathrm{MW}$ BESS

Figure 1. BESS installed in the Sin-Yongin (a); and Seo-Anseong substation (b)

Second, it is necessary to develop a frequency response model that considers the BESS characteristics. The frequency regulation of conventional power plants by a governor and Energy Management System (EMS) is based on the structural characteristics of power plants, so a frequency response model to consider the possibility of using BESS for stabilizing power grid [13], re-establishing the BESS SOC after frequency regulation for delivering power successfully [14], impacts of fast responding characteristic of BESS [15], and so on should be developed. In the case of micro grid scale, BESS applications have been studied as a solution to maintain unstable power of renewable energy resources such as photovoltaic modules [16], and to support supply and demand balance in short time by BESS [17]. There is also research on the enhancement of the stability of a power system through hybrid renewable generation and ESS $[18,19]$. However, as Li-ion battery with high capacity is developed, it is possible to use this battery as BESS for the GW based national power grid to utilize governor-free [20], and auto generation control [21]. In order to take advantage of Li-ion battery such as rapid response time for frequency regulation, the control methodology with proper algorithms and hardware has to be tested and confirmed.

In this study, we developed a dynamic simulation model of the Korean power grid that includes power plants, substations, electric loads and high power batteries. The simulation was used to investigate the performance and output characteristics of a megawatt-scale high-power BESS connected to the power grid for frequency regulation. The operation model of the power grid was simulated to produce the generated power output according to the 24-hour electric load in an actual power grid. It includes the Governor-Free (GF) mode and the Auto Generation Control (AGC) mode connected to EMS. The developed dynamic simulator was connected to FRC hardware and operated to validate the BESS control performance within an actual controller regarding frequency fluctuation caused by any grid disturbance. It could also be applied to develop BESS response models for grid frequency regulation.

\section{DYNAMIC MODELLING}

The developed dynamic simulation model includes a generator model for different types of power plants, GF operation by a governor and AGC operation by an EMS. The real-time dynamic simulator generates dynamic electric load internally based on real data from the Korean power grid. Also, it simulates grid frequency fluctuation and operation modes of power plants responding to load variations. It was modelled to perform 
real-time operation controls for the voltage, current, SOC and output of BESS connected to actual FRC hardware.

\section{Power grid modelling}

Figure 2 depicts the overall modelling configuration of the electric power grid in South Korea. The power grid model includes regionally distributed power plants and substations. In the grid model, substations and major power plants rated for more than $345 \mathrm{kV}$ were modelled, except for those under $154 \mathrm{kV}$ class. The model is therefore composed of 127 substations of $345 \mathrm{kV}$ and $765 \mathrm{kV}$ classes. Each substrate is connected to an active and reactive load. The frequency is calculated based on the load fluctuation.

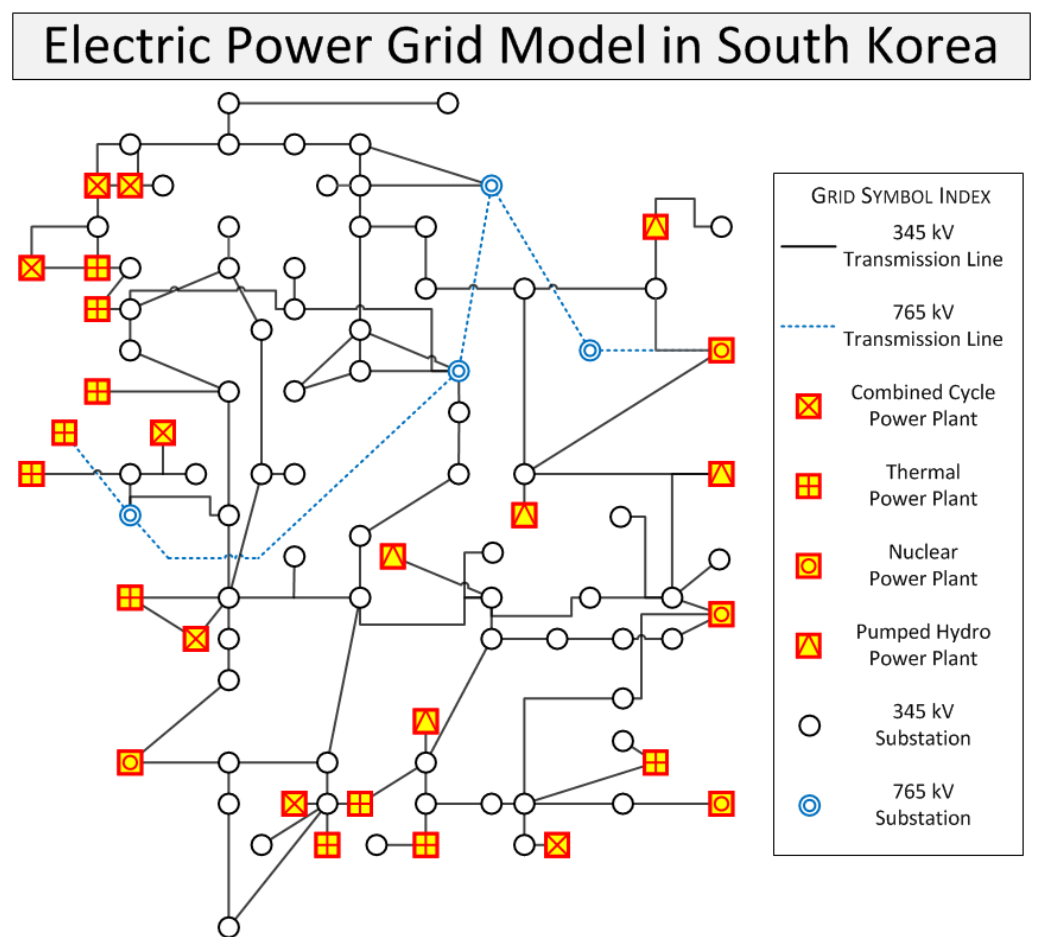

Figure 2. Overall configuration of electric power grid modelling

\section{Power generator modelling}

There are four types of power plants: thermal power plants, combined power plants, nuclear power plants and pumped hydro power plants. Totally 27 power plant models are developed, and each type of plant has its own characteristic time-constant value. GF mode and AGC mode could be selected as the frequency regulation modes for the operation of the power plants. The modelling of power plants and substations was designed based on the regional generation and electric load capacity.

Figure 3a shows the modelling capacity $(61.59 \mathrm{GW})$ of power plants compared to the type and regional installation of actual power generation capacity (86.97 GW) in Korea [22]. Figure $3 \mathrm{~b}$ shows the ratio of the capacity to electric load of the regionally installed power generation facilities. Since the power grid model deals with only substations over $345 \mathrm{kV}$ class and their connected power plants, there are differences compared to the actual grid data. However, focusing on the regional installation distribution, the system has a similar ratio to the actual grid. Also, the composition ratio of the power plant types matches well with that of the actual situations. In the Korean power grid, the regional power loads are largest in Seoul Capital area (33.05\%), followed by Busan/Gyeongnam $(18.67 \%)$ and Chungnam (13.26\%), while the regional power plant installation is highest 
in Busan/Gyeongnam (39.93\%), followed by Chungnam (20.30\%) and in Seoul Capital area $(20.19 \%)$. This unbalanced power supply and demand are one of the power grid characteristics in South Korea and they cause instability of the national power grid.

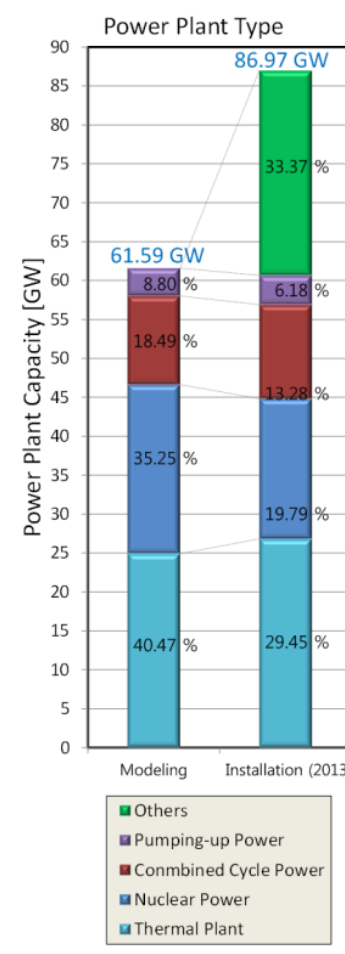

(a) Korea Power Plant Installation

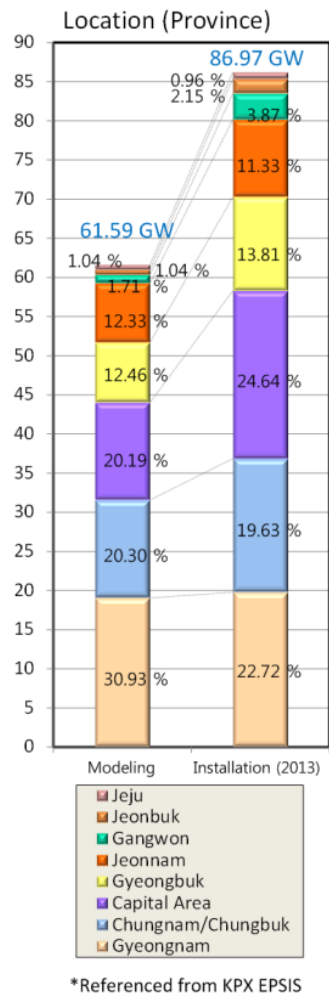

Figure 3. Distribution of regional power generation and electric load capacity

In South Korea, the distribution system uses a common neutral multiple ground. In these conditions, unbalanced current could flow in the neutral, causing high voltage when an imbalance occurs. Regional electric load fluctuation also induces imbalance of the grid and decreases efficiency of power transmission. In this case, electric machines on the grid could malfunction, and the power quality would decrease. Therefore, the BESS for frequency regulation installed in substations could play an important role in stabilizing the power grid.

\section{Electric load modelling}

Characteristics of power plants and substations vary according to the electric power demand and they are operated by regulating the frequency. The dynamic simulation uses daily electric power demand data modelled by referring to real power grid load data. Figure 4 shows that the operation of the power load model matched well with the daily electric power demand trend. The background of the figure depicts monthly power demand data measured in 2014. Comparing the data shows that the operation of the equipment was also operated well within the range of the annual load variation. From 0 AM to 9 AM, the demand is light, and from 9 AM to noon, the load increases. During lunch time, the load drops for an hour. After 1 PM, the load increases to the peak value. The simulation results show that the peak power demand is $61.59 \mathrm{GW}$, and the lowest value is $46.32 \mathrm{GW}$. The power load model has similar characteristics to the real electric load of the power grid and could be very useful for validating an ESS controller for frequency regulation. 


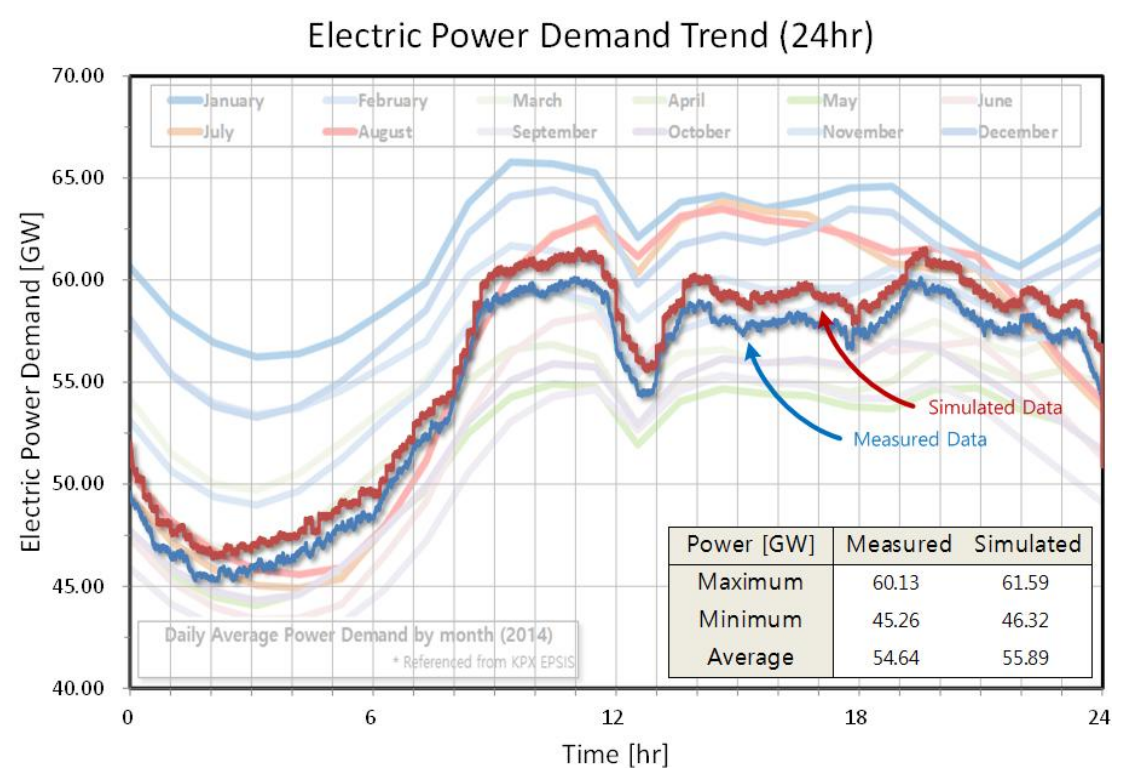

Figure 4. Daily electric power demand modelling data with measured real power grid load data

\section{FREQUENCY CONTROL MODEL}

There is imbalance between the power supply and demand. Since the electric power demand continuously varies over time, a power plant cannot assure the power quality to the grid if it operates with constant output. Therefore, the dynamic simulation model needs a frequency control operation mode for the plants, and it includes GF and AGC operation modes.

\section{Frequency control action}

Figure 5 shows a general sequence of frequency control actions [23]. The frequency control function was simulated by a conventional GF and AGC model which were controlled by EMS of the Korea Power Exchange (KPX). As shown in Figure 5, GF should act within 10 seconds after frequency variation and maintain the output power over 30 seconds. AGC should respond to power demand variation within 30 seconds and generate for 30 minutes. The power plants except for the nuclear power plants are the objects of this study. The EMS of KPX transmits control power values for maintaining $60 \mathrm{~Hz}$ to the power plants every 4 seconds [22].

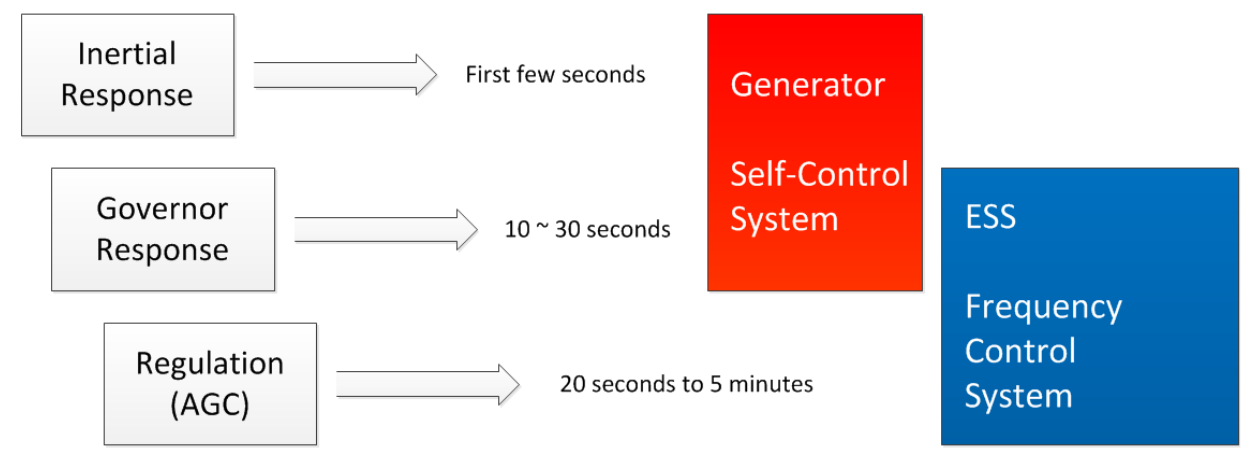

Figure 5. Sequence of frequency control actions

In addition to modelling the operation characteristics of GF and AGC, the grid characteristics with BESS should be well defined. The GF and AGC operation modes of 
the simulator were made according to the power grid characteristics. The power balance of a power system is assured by eqs. (1) and (2):

$$
\begin{gathered}
\frac{d W_{k}}{d t}=P_{g}-P_{c} \\
W_{k}=\frac{J \omega^{2}}{2}
\end{gathered}
$$

The generation power $P_{g}$ and consumption power $P_{c}$ are imbalanced, $W_{k}$ is the kinetic energy of all rotating machines, $J$ is the torque of machines and $\omega$ is the angular speed $(\mathrm{rad} / \mathrm{sec})$. This imbalance leads to variation of the kinetic energy of rotors of the frequency $[24,25]$. If there is no regulating reserve, according to eq. (3), there will be a fluctuation in the frequency of power generation $[26,27]$ :

$$
d f=\frac{d P_{g}}{K_{n}}\left[1-\operatorname{EXP}\left(-\frac{f_{N} K_{n}}{2 W_{k}} t\right)\right]
$$

where $d f$ is the frequency drop $(\mathrm{Hz}), 2 W_{k} / f_{N} K_{n}$ is the time constant $(5-10 \mathrm{sec}), K_{n}$ is the natural control gain of the network $(\mathrm{Hz} / \mathrm{MW})$ and $1 / K_{n}$ is the self-regulation power, which is typically $1-2 \%$ of the total capacity. The power plants have different output response characteristics, different response time according to the time constant of the grid, and different frequency fluctuation trends. The grid constant $1 / K_{n}$ shows the auto control characteristics of the grid and is expressed by the difference of the generation power and consumption power with frequency variation of $0.1 \mathrm{~Hz}$. The Korean power grid uses a grid constant of $5-10 \%$ of the grid capacity $[23,24]$. The simulator uses $5 \%$ as a default grid constant value and is changeable. For this type of grid, GF and AGC operation modes are added to respond to the frequency variation. As mentioned, GF acts within 10 seconds after frequency variation, and AGC operates within 30 seconds after demand power variation.

\section{Governor-free mode}

The power output according to GF operation mode of the simulator is as follows:

$$
d P=\frac{P_{g n}}{S_{G} f_{N}} \times d f=-R_{p} \times d f
$$

where $d P$ is the change in generator output (MW), $P_{g n}$ is the nominal output of the generator (MW), $S_{G}$ is the generator drop $(\%), f_{N}$ is the nominal frequency $(\mathrm{Hz}), d f$ is the change in power system frequency $(\mathrm{Hz})$, and $R_{p}$ is the regulating power $(\mathrm{MW} / \mathrm{Hz})$. Eq. (4) shows the power output according to the generator droop $S_{G}$ [25-27]. The dynamic simulator operates in the GF mode with $S_{G}$ values of 4-5\%. The GF mode operation uses a proportional control method, meaning that the power output is controlled proportionally to the frequency variation. Therefore, if there is no more variation, the power system returns to the previous state as the steady state condition.

\section{AGC regulation mode}

The power output in AGC operation mode is expressed by: 


$$
\begin{gathered}
d P=-K \times A C E-\frac{1}{T_{r}} \int A C E d t \\
A C E=d B+K \times d f \\
d B=P_{\text {generation }}-P_{\text {load }}+P_{\text {import }}-P_{\text {export }}
\end{gathered}
$$

where $d P$ is the output set point of AGC (MW), $K$ is the gain of the power controller, $A C E$ is the area control error, $T_{r}$ is the time constant of $A G C, d B$ is the deviation in the power balance and $d f$ is the change in the power system frequency $(\mathrm{Hz})$. Eq. (5) expresses the variation of the power output by AGC operation [26, 27]. AGC leads to the initialization of the GF mode, which was adopted preliminarily for a system variation within 5-10 minutes. It controls the power output after GF operation for a sufficient time interval.

Figure 6 depicts the simulated response characteristics of GF and AGC operations after a $500 \mathrm{MW}$ power generation loss event. First, the grid maintained the frequency as $60 \mathrm{~Hz}$. Then, the trip of the $500 \mathrm{MW}$ power plant occurred. The GF mode and the AGC mode start to act at points $\mathrm{B}$ and $\mathrm{C}$, respectively. The GF mode reaches a maximum target value after 65 seconds at point $\mathrm{D}$. The output power is proportional to the recovered frequency after the AGC mode starts. Finally, the frequency is recovered to the dead zone $(60 \pm 0.03 \mathrm{~Hz})$ at point E. Then, GF mode is stopped and AGC continuously acts according to the demand variation. The response time of AGC is about 8 seconds between $\mathrm{A}$ and $\mathrm{B}$, and the response time of GF is about 10 seconds between points $\mathrm{A}$ and C. In total, it takes 5 minutes and 30 seconds (A-E) to recover the frequency after the trip of the power plants with the help of AGC and GF modes. It is confirmed that the GF mode responds within 10 seconds, and AGC mode starts to act within 30 seconds and continues for 30 minutes [23].
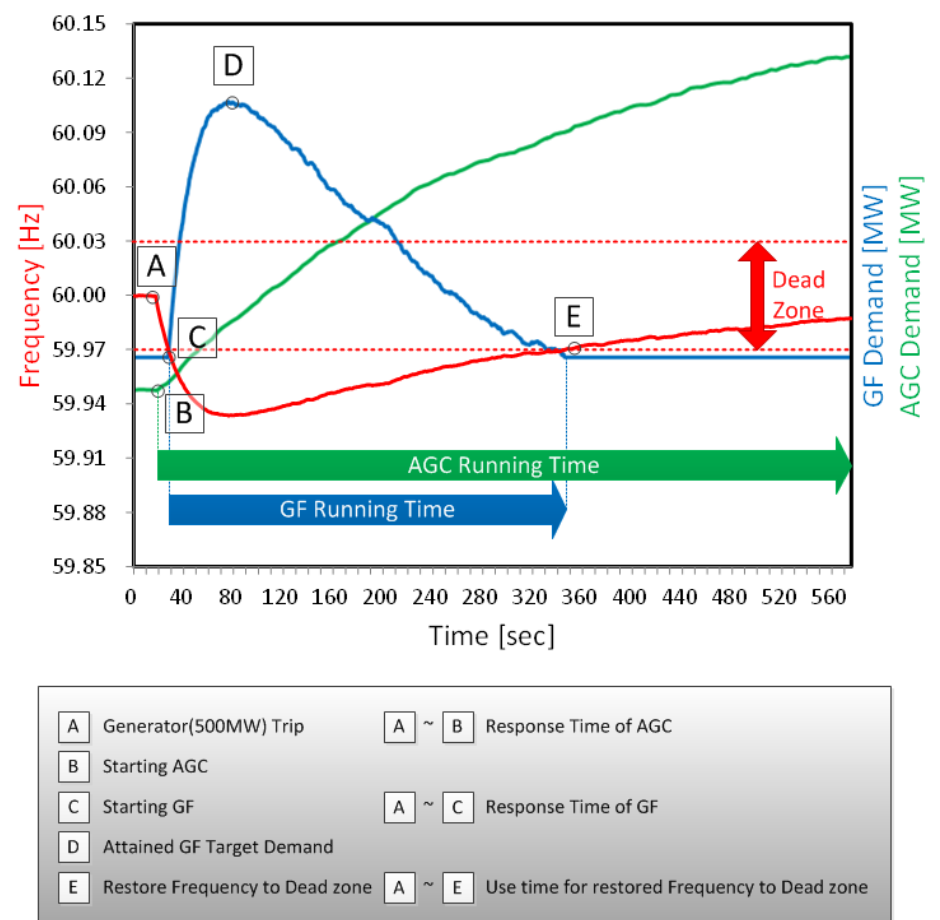

Figure 6. Frequency control actions with GF and AGC after 500 MW generation loss event 


\section{BESS MODELLING}

The BESS connected to the power grid minimizes the output variation and improves the power quality of the grid. When the BESS is installed at a substation, it could solve the load imbalance problem that causes voltage and frequency variations. Also, it could improve the grid efficiency and decrease the peak load and cost of equipment installation. In order to validate the performance of the FR controller, the BESS model is connected to the power grid model of the dynamic simulator. Figure 7 shows a typical discharge curve of a Li-ion battery model with the manufacturer datasheet data (Panasonic HHR650D). The important factors for modelling batteries are the voltage, current and SOC. Modelling the BESS with proper characteristics is also important, as well as matching the characteristics to a real substation of the power grid.

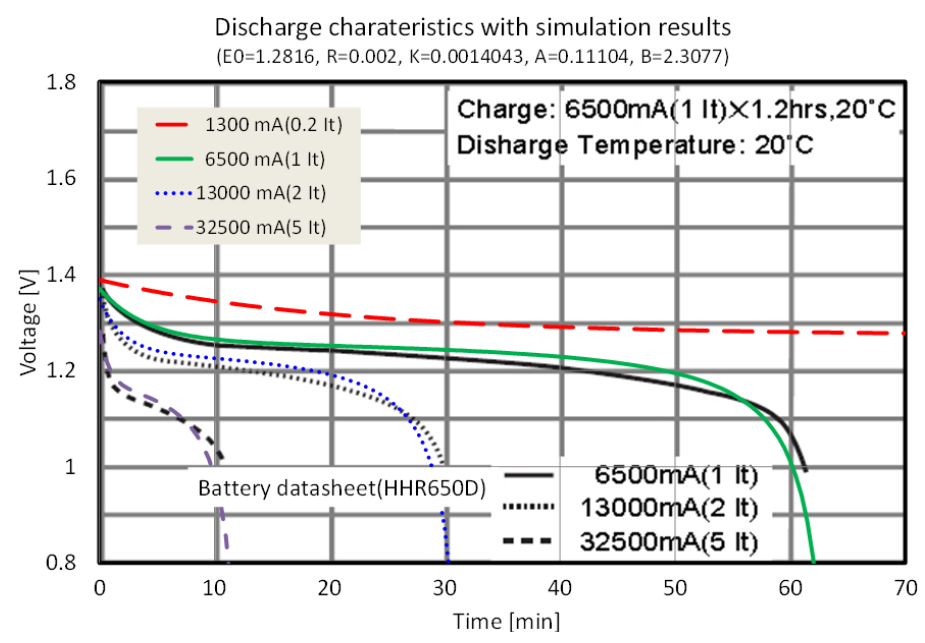

Figure 7. Discharge curve model compared with battery datasheet

As shown in Figure 7, the voltage of the battery decreases when the fully charged battery starts to discharge. The discharge curve forms as a negative exponential curve. After discharging in the exponential voltage range, the nominal voltage state is shown, and the voltage decreases slightly. After the nominal voltage range, the voltage dramatically decreases with an exponential curve and is fully discharged. The modelling of the battery discharge and charge is expressed as eqs. (8) and (9) [28]:

$$
\begin{gathered}
V_{d}=E_{0}-R \times i-K \frac{Q \times\left(\int i d t+i^{*}\right)}{Q-\int i d t}+A \times \operatorname{EXP}\left[-B \int i d t\right] \\
V_{c}=E_{0}-R \times i-K \frac{Q \times \int i d t}{Q-\int i d t}-K \frac{Q \times i^{*}}{\int i d t+0.1 Q}+A \times \operatorname{EXP}\left[-B \int i d t\right]
\end{gathered}
$$

where $V$ is the discharged (d) or charged (c) battery voltage $(\mathrm{V}), E_{0}$ is the battery constant voltage $(\mathrm{V}), i$ is the battery current $(\mathrm{A}), i^{*}$ is the filtered current $(\mathrm{A}), \int i d t$ is the actual battery charge (Ah), $Q$ is the battery capacity (Ah), $A$ is the exponential zone amplitude $(\mathrm{V}), B$ is the exponential zone time constant inverse (1/Ah), $K$ is the polarization constant $(\mathrm{V})$, and $R$ is the internal resistance $(\Omega)$.

The characteristics of the 1-MW battery in the simulation model from eqs. (8) and (9) are shown in Figure 8. This figure shows the voltage, current, SOC and power output of 
the 1 MW battery model with a cycle based on SOC of $90 \%$ of the charge limit and $10 \%$ of the discharge limit. The value of the SOC is controlled within 10 to $90 \%$ according to the control algorithm of the BESS controller for frequency regulation [7]. The charge and discharge quantities are differently defined according to the power grid characteristics. The power output time also depends on the characteristics of the BESS and the capacity of the Power Conditioning System (PCS).

Dynamic Charge-Discharge of BESS Model (1MW, Li-ion Battery)

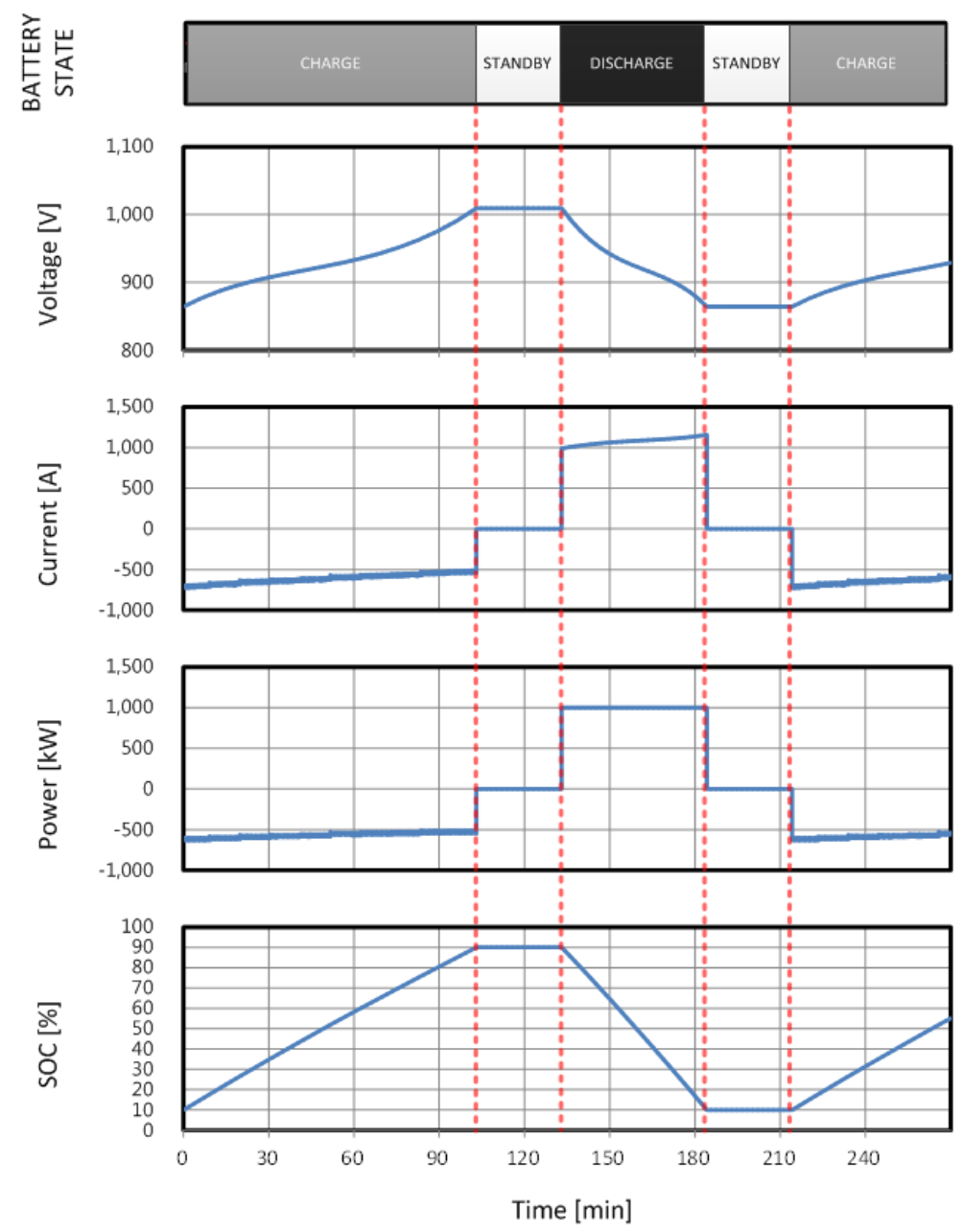

Figure 8. 1 MW BESS operating data $V, I$, SOC and power

\section{OPERATING RESULTS OF DYNAMIC SIMULATION}

In this section, we analyze the daily frequency variation according to the GF and AGC operation modes adapted to the dynamic simulation for responding to the variation power load model. Figure 9 shows how the generation model maintains the frequency in response to the load variation model. When a constant output of $54 \mathrm{GW}$ is generated, the GF and AGC modes operate well according to the frequency fluctuation and load variations. In light load conditions, GF and AGC modes decrease the power generation. At peak loads, the output power increases and the frequency varies in the range of $60 \pm 0.1 \mathrm{~Hz}$. The frequency distribution curve is shown in Figure 10 and gives precise information on the simulated power grid frequency fluctuation.

Figure 10 shows the measured amplitude of the grid frequency when GF and AGC mode are operated from $1 \mathrm{AM}$ to $11 \mathrm{PM}$. KEPCO has a rule of maintaining the frequency 
retention rate in the range of $60 \pm 0.1 \mathrm{~Hz}$. The calculated frequency retention rate of the simulator is obtained by eq. (10) [29]:

Frequency retention rate $=\frac{\text { Operation time in the range }(60 \pm 0.1 \mathrm{~Hz})}{\text { Total operation time }} \times 100(\%)$

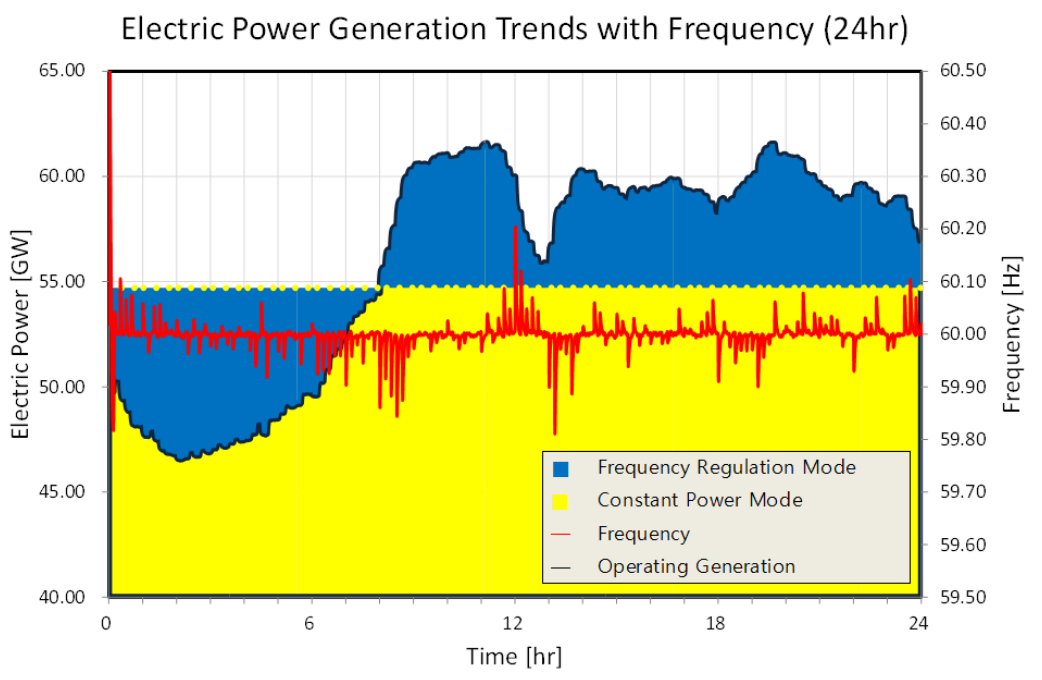

Figure 9. Daily operation trends of electric power demand, generation, and frequency

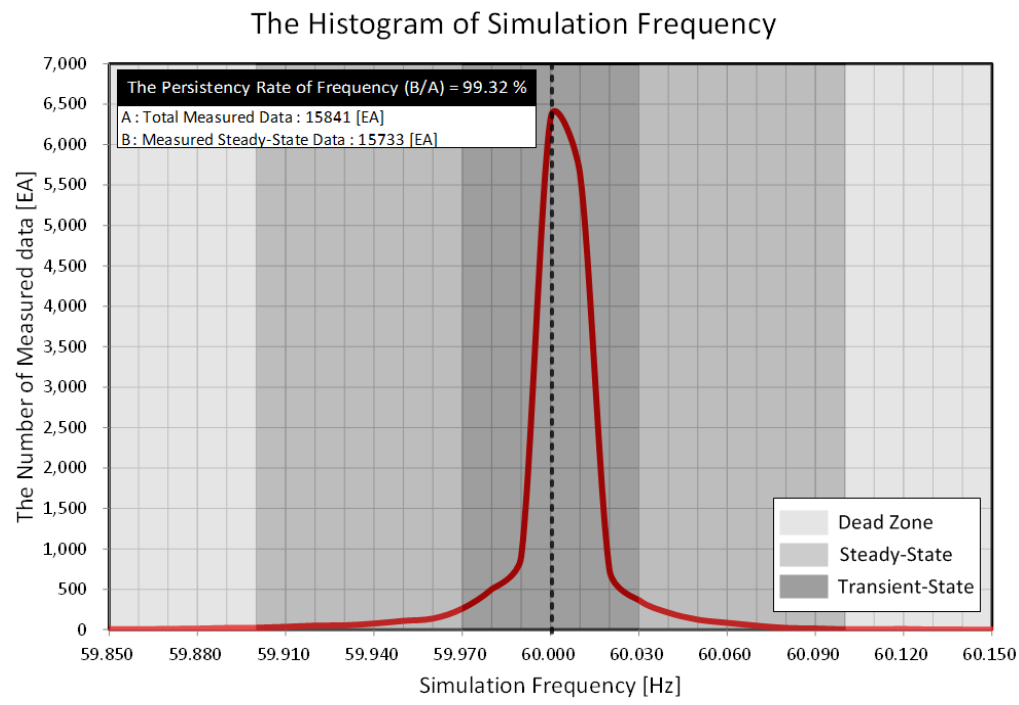

Figure 10. Gaussian distribution of electric power frequency

The value obtained from the simulation model is $99.32 \%$. In the dead zone of the range of $60 \pm 0.03 \mathrm{~Hz}$, the value is $93.01 \%$. Other than the dead zone, the steady-state area accounts for $6.31 \%$. According to KPE data, the actual frequency retention rate is regulated within $99.9 \pm 0.1 \%$. In South Korea, the rates were maintained as 99.98, 99.99 and $99.99 \%$ in 2012, 2013 and 2014, respectively [29]. The frequency retention rate of the simulator is $99.32 \%$, and there is an error of $0.66-0.67 \%$ between the actual data and the simulation result. This might be caused by the unconsidered power plants rated for less than $345 \mathrm{kV}$ and by the characteristics of the modified electric power demand model.

The simulation results of frequency variation in three different grid constants (Kc grid) are compared with real data in Figure 11. In a 500 MW generation loss event, 
the frequency slope is simulated within 4 to $8 \%$ of grid constant value. The general frequency profile is shown as similar order to the real data.

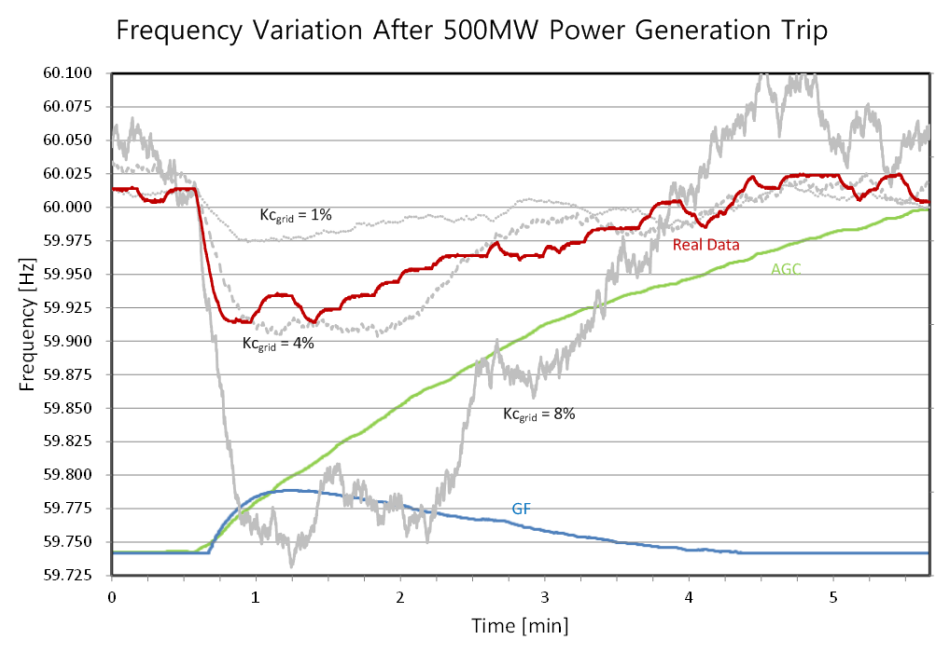

Figure 11. Simulation frequency profile compared with real data

\section{APPLICATION OF FRC PERFORMANCE TEST}

Figure 12 shows the KEPCO regulation for interconnecting the actual power grid and BESS for FR [30, 31]. The control command is transferred by the Main Power Management System (MPMS) from KPX to low level controllers. Local Power Management System (LPMS) receives frequency information through a Power Quality (PQ) meter that measures the frequency and Battery Management System (BMS) output and distributes the FRC participation ratio to Frequency Regulation Controller Master (FRCM). The FRC receives battery information from Power Condition System (PCS) and sends an output control command according to battery SOC. The response time of the process from the control command to the output is calculated as $t=t 5-t 1$ and is limited to under $200 \mathrm{~ms}$ by KEPCO regulations [31]. The developed dynamic simulator could be connected with the frequency regulation controller and work in real time for FRC performance testing under the various operating conditions of the power grid.

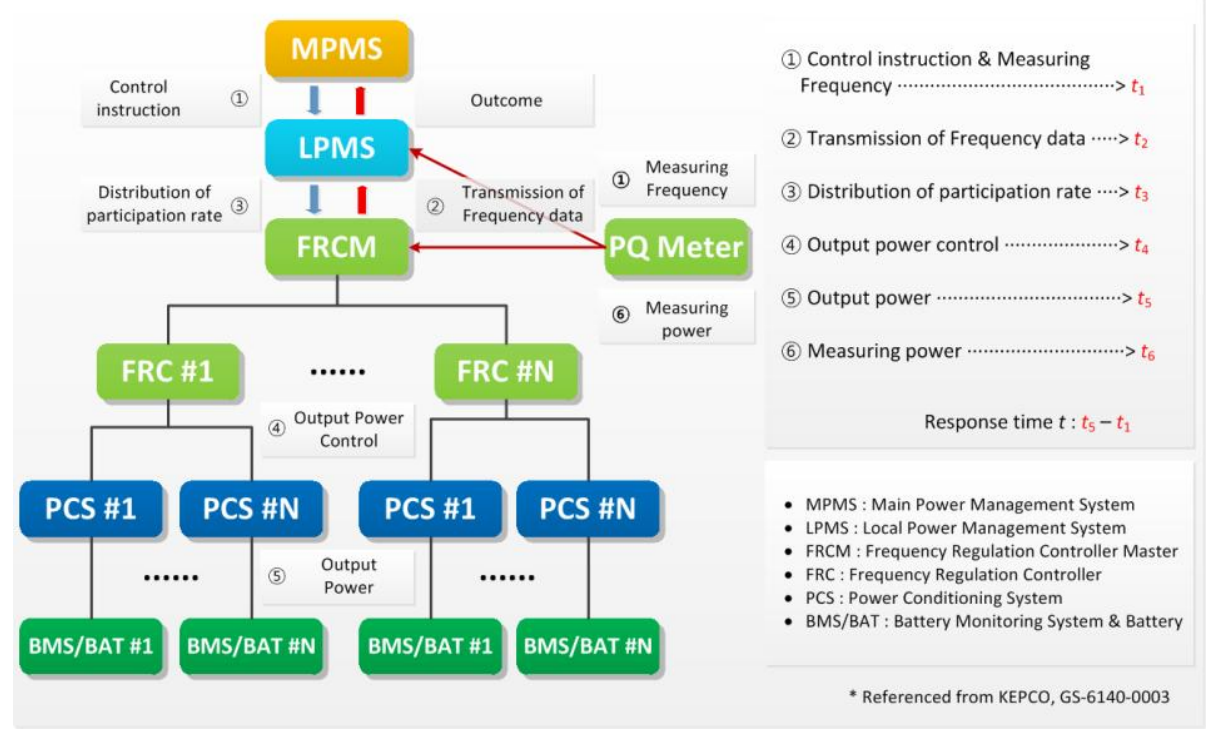

Figure 12. Sequence of frequency regulation with BESS in MW class 
Figure 13 shows an overall integration diagram of a 24 MW FRC and dynamic simulation model. The FRC and the simulator have a PLC DNP module and XMTRPLC module. They send and receive signals through DNP 3.0 communication. There are three FRC performance test procedures: sending analog signals such as the grid frequency from the simulator to the FRC, sending analog and digital signals to the simulator such as the target values of the battery power demand calculated by FRC logic, and finally, sending response signals of the battery power output to the FRC. The output control process of BESS by FRC occurred as follows. The simulated grid frequency and battery information are sent to the FRC. The FRC distinguishes between the steady state and the transient state through the received frequency and sends an output control command to the simulator [9]. The simulator receives the command and calculates the BAT output target value in the PCS model and grid model. Then, it sends the BAT output and the controlled frequency to the FRC. The duration of this process is limited to less than $200 \mathrm{~ms}$ by KEPCO regulations.

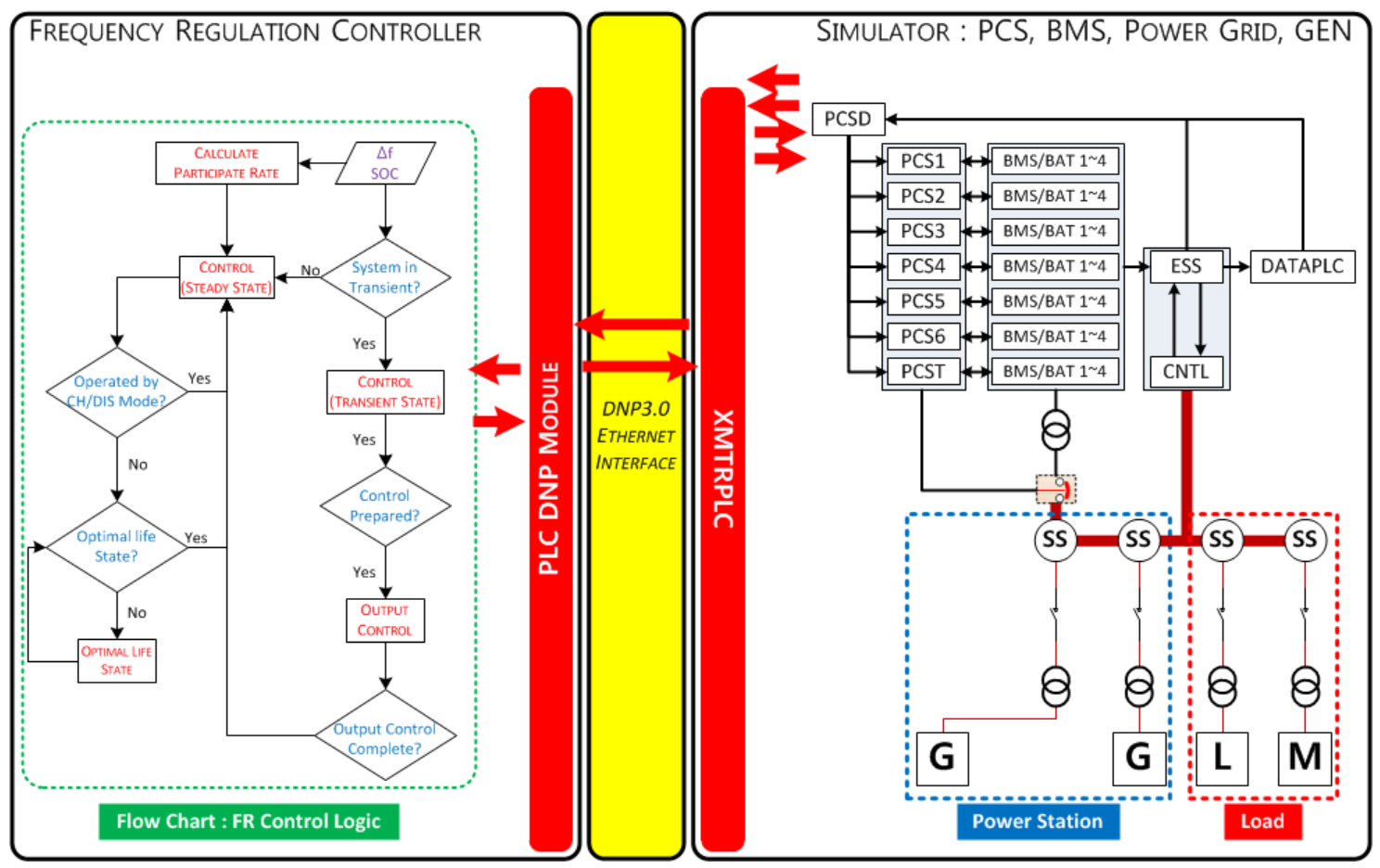

Figure 13. Overall integration diagram of $24 \mathrm{MW} F R C$ and its dynamic simulation model

\section{CONCLUSIONS}

In this study, we developed a dynamic simulation model of the Korean power grid, including power plants, substations, electric load, and high power batteries. The simulation was used to investigate the performance and the output characteristics of a megawatt-scale high-power BESS connected to the power grid for frequency regulation. The operational model of the power grid was simulated to produce the generated power output according to 24-hour electric power demand of the actual power grid. It includes the GF mode and the AGC mode connected to the EMS. The simulator includes thermal power plants, combined power plants, nuclear power plants and pumped hydro power plant, and a megawatt-class high-power BESS for frequency regulation.

The installation capacity of the power grid was $87.17 \mathrm{GW}$, and the peak load was $77.30 \mathrm{GW}$. The maximum power output was about $61.59 \mathrm{GW}$, while the minimum was 46.32 GW. The commercialized real-time dynamic simulation software ProTRAX was 
used for the dynamic modelling. The simulation was conducted to observe the operation characteristics of the frequency control system during breakdown of power plants, in GF and AGC operation, and with the battery energy storage system connected. The results showed that the model was valid for each power plant breakdown simulation. This confirmed that the output power and frequency controls of the battery operated quite well during simulations. When a constant output of $54 \mathrm{GW}$ was generated, the GF and AGC modes operated well according to the frequency fluctuation and load variations. The frequency retention rate of the simulation model was $99.32 \%$, and there was only a $0.66-0.67 \%$ error between the actual data and the simulated data.

In this simulation, there were unconsidered power plants rated for less than $345 \mathrm{kV}$, which caused a capacity difference. Although there is regional imbalance of the power supply and demand in the power grid model, the voltage stabilization could not be accurately modelled by BESS for FR. Further study is needed to model substations rated under $154 \mathrm{kV}$ and related facilities in order to obtain a more precise power grid and to test the developed high precision frequency regulation controller.

\section{NOMENCLATURE}

$\begin{array}{llc}A & \text { Exponential zone amplitude } & {[\mathrm{V}]} \\ A C E & \text { Area control error } & {[\mathrm{MW}]} \\ B & \text { Exponential zone time constant inverse } & {[1 / \mathrm{Ah}]} \\ d B & \text { Deviation in power balance } & {[\mathrm{MW}]} \\ d f & \text { Frequency drop } & {[\mathrm{Hz}]} \\ d P & \text { Power output } & {[\mathrm{MW}]} \\ E_{0} & \text { Battery constant voltage } & {[\mathrm{V}]} \\ f_{N} & \text { Nominal frequency } & {[\mathrm{Hz}]} \\ i & \text { Battery current } & {[\mathrm{A}]} \\ i^{*} & \text { Filtered current } & {[\mathrm{A}]} \\ J & \text { Torque of machine } & {[\mathrm{Nm}]} \\ K & \text { Polarization constant } & {[\mathrm{V}]} \\ K_{n} & \text { Natural control gain of the network } & {[\mathrm{Hz} / \mathrm{MW}]} \\ P_{c} & \text { Consumption power } & {[\mathrm{MW}]} \\ P_{g} & \text { Generation power } & {[\mathrm{MW}]} \\ P_{g n} & \text { Nominal output of generator } & {[\mathrm{MW}]} \\ Q & \text { Battery capacity } & {[\mathrm{Ah}]} \\ R & \text { Internal resistance } & {[\mathrm{Ohm}]} \\ R_{p} & \text { Regulating power per df } & {[\mathrm{MW} / \mathrm{Hz}]} \\ S_{G} & \text { Generator drop } & {[\%]} \\ S O C & \text { State of Charge } & {[\%]} \\ T_{r} & \text { Time constant of AGC } & {[\mathrm{s}]} \\ V & \text { Battery voltage } & {[\mathrm{V}]} \\ W_{k} & \text { Kinetic energy } & {[\mathrm{J}]}\end{array}$

\section{Greek letters}

$\omega$

Angular speed

$[\mathrm{rad} / \mathrm{sec}]$

\begin{tabular}{ll}
\multicolumn{2}{c}{ Abbreviations } \\
AGC & Auto Generation Control \\
EMS & Energy Management System \\
FRC & Frequency Regulation Controller \\
GF & Governor-Free
\end{tabular}




\section{REFERENCES}

1. Rebours, Y. G., Kirschen, D. S., Trotignon, M. and Rossignol, S., A Survey of Frequency and Voltage Control Ancillary Services-Part I: Technical Features, Power Systems, IEEE Transactions on, Vol. 22, No. 1, pp 350-357, 2007.

2. Stenzel, P., Koj, J. C., Schreiber, A., Hennings, W. and Zapp, P., Primary Control Provided by Large-scale Battery Energy Storage Systems or Fossil Power Plants in Germany and Related Environmental Impacts, J. Energy Storage, in press, 2016, http://dx.doi.org/10.1016/j.est.2015.12.006

3. Rebours, Y. G., Kirschen, D. S., Trotignon, M. and Rossignol, S., A Survey of Frequency and Voltage Control Ancillary Services-Part II: Economic Features, Power Systems, IEEE Transactions on, Vol. 22, No. 1, pp 358-366, 2007.

4. Fleer, J. and Stenzel, P., Impact Analysis of Different Operation Strategies for Battery Energy Storage Systems Providing Primary Control Reserve, Journal of Energy Storage, in press, 2016, http://dx.doi.org/10.1016/j.est.2016.02.003

5. Aditya, S. K. and Das, D., Battery Energy Storage for Load Frequency Control of an Interconnected Power System, Electric Power System Research, Vol. 58, No. 3, pp 179-185, 2001, http://dx.doi.org/10.1016/S0378-7796(01)00129-8

6. Han, J. B., Kook, K. S. and Chang, B., A Study on the Criteria for Setting the Dynamic Control Mode of Battery Energy Storage System in Power Systems, The Transactions of The Korean Institute of Electrical Engineers, Vol. 62, No. 4, pp 444-450, 2013, http://dx.doi.org/10.5370/KIEE.2013.62.4.444

7. Yun, J. Y., Yu, G. R., Kook, K. S., Rho, D. H. and Chang, B., SOC-based Control Strategy of Battery Energy Storage System for Power System Frequency Regulation, The Transactions of The Korean Institute of Electrical Engineers, Vol. 63, No. 5, pp 622-628, 2014, http://dx.doi.org/10.5370/KIEE.2014.63.5.622

8. Lim, G. P., Han, H. G., Chang, B. H., Yang, S. K. and Yoon, Y. B., Demonstration to Operate and Control Frequency Regulation of Power System by 4 MW Energy Storage System, The Transactions of the Korean Institute of Electrical Engineers, Vol. 63, No. 3, pp169-177, 2014, http://dx.doi.org/10.5370/KIEEP.2014.63.3.169

9. Del Castillo Jr, M., Lim, G. P., Yoon, Y. and Chang, B., Application of Frequency Regulation Control on the 4 MW/8 MWh Battery Energy Storage System (BESS) in Jeju Island, Republic of Korea, Journal of Energy, Vol. 1, No. 6, pp 287-295, 2014.

10. Jeon, W. J., Lim, G. P., Kim, C. W., Chang, B. H. and Yoon, Y. B., A Study on Effects of ESS for Frequency Regulation in Juju Island, Proceedings of KIEE, The Korean Institute of Electrical Engineers, pp 16-18, 2014.

11. Hur, W., Moon, Y., Shin, K., Kim, W., Nam, S. and Park, K., Economic Value of Li-ion Energy Storage System in Frequency Regulation Application from Utility Firm's Perspective in Korea, Energies, Vol. 8, No. 6, pp 5000-5017, 2015, http://dx.doi.org/10.3390/en8065000

12. Koller, M., Borsche, T., Ulbig, A. and Andersson, G., Review of Grid Applications with the Zurich 1 MW Battery Energy Storage System, Electric Power Systems Research, Vol. 120, pp 128-135, 2015, http://dx.doi.org/10.1016/j.epsr.2014.06.023

13. Košický, T., Kolcun, M. and Beňa, L., Influence of State of Charge Level on Frequency Control Reserve Provision by Energy Storage System, Transactions on Electrical Engineering, Vol. 4, No. 2, pp 36-41, 2015.

14. Stroe, D. I., Knap, V., Swierczynski, M., Stroe, A, I. and Teodorescu, R., Suggested Operation of Grid-Connected Lithium-ion Battery Energy Storage System for Primary Frequency Regulation: Lifetime Perspective, Energy Conversion Congress and Exposition (ECCE), 2015 IEEE, pp 1105-1111, 2015, http://dx.doi.org/10.1109/ECCE.2015.7309813 
15. Borsche, T. S., Ulbig, A. and Andersson, G., Impact of Frequency Control Reserve Provision by Storage Systems on Power System Operation, Proceedings $19^{\text {th }}$ IFAC World Congress, Vol. 19, pp 4038-4043, 2014, http://dx.doi.org/10.3182/20140824-6-za-1003.02257

16. Cellura, M., Di Gangi, A. and Orioli, A., Assessment of Energy and Economic Effectiveness of Photovoltaic Systems Operating in a Dense Urban Context, Journal of Sustainable Development of Energy, Water and Environment Systems, Vol. 1, No. 2, pp 109-121, 2013.

17. Aghamohammadi, M. R. and Abdolahinia, H., A New Approach for Optimal Sizing of Battery Energy Storage System for Primary Frequency Control of Islanded Microgrid, International Journal of Electrical Power \& Energy Systems, Vol. 54, pp 325-333, 2014, http://dx.doi.org/10.1016/j.ijepes.2013.07.005

18. Morel, J., Obara, S. Y. and Morizane, Y., Stability Enhancement of a Power System Containing High-Penetration Intermittent Renewable Generation, Journal of Sustainable Development of Energy, Water and Environment Systems, Vol. 3, No. 2, pp 151-162, 2015.

19. Pourmousavi, S. A. and Nehrir, M. H., Real-time Central Demand Response for Primary Frequency Regulation in Microgrids, Smart Grid, IEEE Transactions on, Vol. 3, No. 4, pp 1988-1996, 2012.

20. Cho, S. M., Jang, B. H., Yoon, Y. B., Jeon, W. J. and Kim, C. W., Operation of Battery Energy Storage System for Governor Free and its Effect, The Transactions of The Korean Institute of Electrical, Vol. 64, No. 1, pp 16-22, 2015, http://dx.doi.org/10.5370/kiee.2015.64.1.016

21. Gorripotu, T. S., Sahu, R. K. and Panda, S., AGC of a Multi-area Power System under Deregulated Environment using Redox Flow Batteries and Interline Power Flow Controller, Engineering Science and Technology, an International Journal, Vol. 18, No. 4, pp 555-578, 2015.

22. Electric Power Statistics Information System, Korea Electric Exchange, http://epsis.kpx.or.kr/epsis/, [Accessed: 13-October-2014]

23. Matevosyan, J., Application of KERMIT in the DOE LTS Process, ERCOT, 2014

24. Song, K. Y., New Power System Engineering, Doing-Il Publisher, pp 271-267, 2013.

25. Vuorinen, A., Planning of Optimal Power Systems, Ekoenergo Oy, pp 3-37, 2008.

26. NERC BAL-003-1, Balancing and Frequency Control, pp 2-37, 2011.

27. NERC BAL-003-1, Frequency Response Reliability Standard, pp 1-37, 2015.

28. Tremblay, O. and Dessaint, L. A., Experimental Validation of a Battery Dynamic Model for EV Applications, World Electric Vehicle Journal, Vol. 3, No. 1, pp 1-10, 2009.

29. Byun, S. H., Shin, J. S. and Joo, H. R., A Research of Frequency Quality Evaluation in Power System using Standard Deviation, Proceedings of KIEE, The Korean Institute of Electrical Engineers, pp 133-134, 2009.

30. GS-6140-0002, Lithium Secondary Battery for Frequency Regulation; Container Type, General Technical Specifications of KEPCO, 2014.

31. GS-6140-0003, Power Conditioning System for Frequency Regulation; Container Type, General Technical Specifications of KEPCO, 2014. 